\section{AB1176 UTILITY OF REDOSER TOOL IN DOSE OPTIMIZATION OF BIOLOGICAL THERAPY IN PATIENTS WITH RHEUMATOID ARTHRITIS IN CLINICAL PRACTICE}

A. M. Cabezas-Lucena ${ }^{1}$, M. Morales-Águila ${ }^{1}$, S. Manrique Arija ${ }^{1,2}$, C. FuegoVarela ${ }^{3}$, L. Cano Garcia ${ }^{1}$, N. Al Mashhadani ${ }^{1}{ }^{1}$ Hospital Regional Universitario de Málaga, Málaga, Spain; ${ }^{2}$ Institute for Biomedical Research in Malaga (IBIMA), MÁLAGA, Spain; ${ }^{3}$ Hospital Universitario De Jerez, Jerez de la Frontera, Spain

Objectives: To describe the characteristics of patients with rheumatoid arthritis (RA) in dose reduction of biological therapy (BT) in clinical practice and identify possible factors associated with the time in dose reduction and verify the utility of REDOSER tool. Methods: Design: A retrospective, observational longitudinal study under conditions of clinical practice. Patients: RA in BT dose reduction between 2007- 2019 were selected. Inclusion criteria: RA according to ACR 2010 criteria which have been initiated $\mathrm{BT}$ dose reduction. Patients with $\mathrm{BT}$ are followed prospectively every 3-4 months in a specialized outpatient unit of BT dose reduction with a pre-established protocol for data collection and registered in a database. Variables: Primary: Time in reduction: was defined as the time in which patients maintained the BT optimization and Relapse at 12 and $\mathbf{2 4}$ months: percentage of patients who, after starting BT optimization, return to the previous or standard dose. Secondary variables: REDOSER: Appropriate, Doubtful and Inappropriate (If dose reduction was adequate according to the REDOSER tool applied retrospectively were evaluated). Other variables: Demographic, clinical-anaIytical: time of disease evolution, RF, anti CCP antibodies, Number of Tender Joints, Number of swollen joints, erosions, activity index (DAS28, SDAI, CDAI) and physical function (HAQ). Previous treatments. Statistical Analysis: descriptive, bivariate using $\mathrm{x} 2$ and T-Student among patients with and without relapse at 24 months and multivariate linear regression to identify independent variables associated with the time in BT dose reduction (DV: time in reduction).

Results: 59 patients with RA were included. Table 1 shows the main characteristics of the subjects. The average (SD) of optimization in months was 17.9 (17.7). Ten patients (16.9\%) relapsed at 12 months and $16(27.1 \%)$ at 24 months. The mean (SD) of DAS28 and SDAl of patients who relapsed at 24 months was higher compared to baseline DAS28 (2.3 [0.9] vs. 1.5 [0.8]; $p=0.015)$ and SDAI (7.8 [6.3] versus 3.3 [1.6]; $p$ 0.05). These patients who relapsed at 24 months compared to patients who did not have more erosions at the start of BT ( $p=$ $0.004)$, longer duration of disease $(p=0.072)$ and greater baseline activity of DAS28 $(p=0.017)$, of SDAI $(p=0.030)$ and CDAI $(p=0.036)$. After simulating the REDOSER tool to all patients at the beginning of the OBT, 28 patients $(56 \%)$ were "Appropriate", 20 (40\%) "Doubtful" and $2(4 \%)$ "Inappropriate" of which they continue in OBT at the conclusion of study 22,10 and 0 , respectively $(p=$ 0.020 ). In the multivariant analysis, the independent variables that are associated with time in dose reduction of BT were baseline DAS28 ( $\beta=-0.660,95 \%$ $\mathrm{Cl}[2.7-14.0] ; p=0.014)$ and age ( $\beta=-0.800,95 \% \mathrm{Cl}[0.8-0.0] ; p=0.038)$.

Conclusion: The majority of the patients with RA who initiate BT dose reduction maintain the optimization after 24 months. REDOSER can be useful in clinical practice to assess the BT optimization in patients with RA. A longer time in BT dose reduction was associated with lower values of DAS28 at the beginning and younger age of the patients.

Figure 1:

\begin{tabular}{lc}
\hline Variable & Patients $n=59$ \\
\hline Epidemiological characteristics & \\
Sex, female, $n(\%)$ & $47(79.7)$ \\
Age in years, mean (SD) & $59,6(12.6)$ \\
Evolution time, months, mean (SD) & $172,0(90.5)$ \\
Diagnostic delay, months, median (p25-p75) & $12,0(5.9-24.0)$ \\
Time to OBT, months, mean (SD) & $17,9(17.7)$ \\
Percentage of patients in OBT until index date, $n(\%)$ & $32(65.3)$ \\
Clinical and analytical characteristics & \\
RF positive, $n(\%)$ & $46(80.7)$ \\
Anti CCP antibodies positive, $n(\%)$ & $45(78.9)$ \\
Double seropositivity, $n$ (\%) & $42(73.7)$ \\
Erosions, $n(\%)$ & $42(73.7)$ \\
Treatment at dose reduction beginning & \\
sDMARD & \\
Methotrexate, $n(\%)$ & $26(44.1)$ \\
Sulfasalazine, $n(\%)$ & $7(11.9)$ \\
Leflunomide, $n(\%)$ & $2(3.4)$ \\
bDMARD & \\
Abatacept, $n(\%)$ & $1(1.7)$ \\
Etanercept, $n(\%)$ & $28(47.5)$ \\
Adalimumab, $n(\%)$ & $4(6,8)$ \\
Golimumab, $n(\%)$ & $1(1.7)$ \\
Certolizumab, $n(\%)$ & $1(1.7)$ \\
Tocilizumab, $n(\%)$ & $22(37.3)$ \\
REDOSER (adecuate reduction) $n(\%)$ & $28(56.0)$ \\
\hline
\end{tabular}

Disclosure of Interests: None declared

DOI: 10.1136/annrheumdis-2020-eular.5875

\section{$\mathrm{AB} 1177$ \\ METHODOLOGICAL ASPECTS OF DESIGN, ANALYSES AND REPORTING OF STUDIES WITH WORK PARTICIPATION AS OUTCOME DOMAIN IN PATIENTS WITH INFLAMMATORY ARTHRITIS: RESULTS OF TWO SYSTEMATIC LITERATURE REVIEWS INFORMING EULAR POINTS TO CONSIDER}

A. Alunno ${ }^{1}$, M. L. Marques ${ }^{2,3}$, A. Boonen ${ }^{4}$, L. Falzon ${ }^{5}$, S. Ramiro ${ }^{3,6}$, P. Putrik ${ }^{4}{ }^{1}$ University of Perugia, Perugia, Italy; ${ }^{2}$ Centro Hospitalar e Universitário de Coimbra, Coimbra, Portugal; ${ }^{3}$ LUMC, Leiden, Netherlands; ${ }^{4}$ MUMC, Maastricht, Netherlands; ${ }^{5}$ Center for Personalized Health, Northwell Health, New York, United States of America; ${ }^{6}$ Zuyderland MC, Heerlen, Netherlands

Background: Inflammatory arthritis (IA) has substantial impact on work participation (WP). However, methodological issues hamper interpretation, comparison and meta-analyses of studies with WP as outcome domain. Sources of heterogeneity and methodological choices should be assessed in order to improve the quality of future studies.

Objectives: To summarize methodological choices in studies with WP as outcome domain in IA and other chronic diseases.

Methods: A EULAR task force on 'points to consider (PtC) when designing, analysing and reporting studies with WP as outcome domain among patients with IA' outlined the scope of the systematic literature review (SLR) and identified 6 areas of potential concern (Table 1). Two searches were conducted (Figure 1): Search 1 (S1): original studies in IA (RCTs and longitudinal prospective observational studies); S2: systematic reviews in other chronic diseases. Two reviewers independently identified eligible studies and extracted data for the pre-defined methodological areas.

Table 1. Methodological issues across the 6 pre-defined areas (search 1 , $\mathrm{n}=62$ )

Area Methodological issues

1. Study design $\quad-16 / 62(26 \%)$ and $8 / 62(13 \%)$ studies aligned the target population and sample size with the study's work outcome.

$9 / 39(24 \%)$ of the interventional studies aimed to assess changes of work status (employment/disability) over a very short follow-up time ( $\leq 6$ months).

2. Work outcome $\quad-7 / 33(21 \%)$ of studies defined work status.

domains $\quad-30 / 30(100 \%), 38 / 38(100 \%)$ and $7 / 7(100 \%)$ defined absenteeism, presenteeism and unpaid work, respectively.

3. Work outcome $\quad-22 / 62(35 \%)$ studies used non-validated instruments (e.g. measurement self-reported days of sick leave/impact of disease on productivity, instruments $\quad n=16 / 62,26 \%)$.

4. Contextual factors - 54/62 (87\%) studies neglected work-related contextual factors.

5. Data analyses Of the studies measuring absenteeism and/or presenteeism - 10/38 (26\%) accounted for skewness of the work outcome. -30/38 (79\%) took interdependence between outcomes as part of work productivity and activity impairment questionnaire into account.

6. Reporting $\quad-62 / 62(100 \%)$ studies reported the size and characteristics of the (sub)groups in which the analyses were performed. $1 / 62(2 \%)$ reported loss to follow-up and work-related reasons for drop-out.

$42 / 62(68 \%)$ studies presented aggregated results; $11 / 62(18 \%)$ presented results as percentages according to meaningful thresholds; $9 / 62$ (14\%): both forms.

$21 / 24(88 \%)$ studies reporting productivity costs, provided data on natural volumes (days/hours) used to calculate costs.

${ }^{*}$ The number of studies in denominators vary by methodological issue.

Results: We included 62 original studies in IA (23 RCTs, 16 interventional and 23 non-interventional observational studies) and 28 SLRs in other chronic diseases. The methodological aspects most often neglected in original studies (Table 1) were: the choice of the study design in relation to the work-related study objective; definitions of the WP outcome domains considered; accounting for skewness of the work outcome; consideration of work-related contextual factors; reporting attrition and its reasons and reporting both aggregated results as well as proportions of individuals based on predefined meaningful thresholds. SLRs on other chronic diseases confirmed high heterogeneity and methodological flaws in all the 6 key methodological areas without identifying new problematic areas.

Conclusion: High methodological heterogeneity was observed in studies with WP. Consensus around the key methodological aspects is needed to homogenise and improve the quality of future studies. This review informs the EULAR $\mathrm{PtC}$ for the conduction and reporting of studies with WP as an outcome domain in IA 


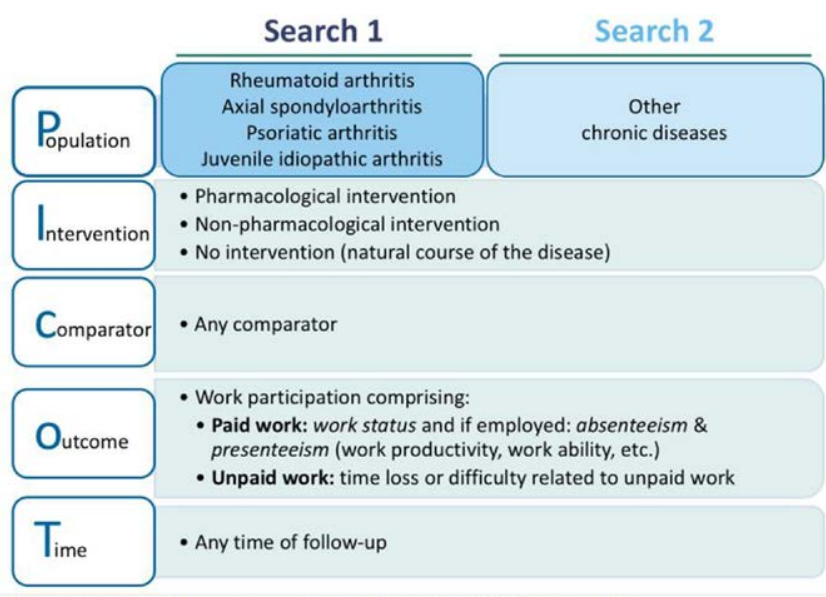

Figure 1. Search strategy 1 and 2 according to the PICOT framework.

Disclosure of Interests: Alessia Alunno: None declared, Mary Lucy Marques: None declared, Annelies Boonen Grant/research support from: AbbVie, Consultant of: Galapagos, Lilly (all paid to the department), L. Falzon: None declared, Sofia Ramiro Grant/research support from: MSD, Consultant of: Abbvie, Lilly, Novartis, Sanofi Genzyme, Speakers bureau: Lilly, MSD, Novartis, Polina Putrik: None declared

DOI: 10.1136/annrheumdis-2020-eular.4730

\section{AB1178 1 AN AUDIT OF ORIGINATOR ADALIMUMAB TO BIOSIMILAR SWITCH IN TWO HOSPITALS}

R. Mazumder ${ }^{1}$, M. Loke ${ }^{1}$, C. Mukhtyar ${ }^{1}$, K. Gaffney ${ }^{1}$, E. Balogh ${ }^{2}$, E. Sekaran ${ }^{2}$, M. Sultana ${ }^{3}$, M. Odonkor ${ }^{2}$, K. Miles $^{1} .{ }^{1}$ Norfolk \& Norwich University Hospital, Norwich, United Kingdom; ${ }^{2}$ Broomfield Hospital, Broomfield, United Kingdom; ${ }^{3}$ University of Essex, Colchester, United Kingdom

Background: Biological drugs have revolutionized the treatment of immune-mediated inflammatory diseases (IMIDs). Current guidelines reserve these drugs for patients with severe refractory disease.

Biologic drugs are expensive, but as they reach patent expiry, the introduction of lower-cost biosimilars reduces their impact on health care budgets. It is estimated that NHS England could save $£ 300$ million by 2021 following the recent launch of adalimumab biosimilars [1]. As part of this process, there has been a mandatory switch of originator adalimumab to biosimilar adalimumab throughout the U.K.

Objectives: To evaluate the impact of the switch to biosimilar adalimumab in individuals with inflammatory arthritis at two NHS trusts in the East of England and calculate the proportion and reasons for switch back to originator adalimumab or a second biosimilar at 12 weeks.

Methods: Both hospitals ran dedicated 'switch' clinics. All patient records were reviewed retrospectively.

Results: 855 patients with different IMID switched from originator to biosimilar over 13 months. At 12 weeks, 730 patients (85\%) maintained the switch, 71 patients $(8.7 \%)$ switched back to the originator, and 54 patients $(6.3 \%)$ switched to other biosimilars of the same drug.

Table 1. Primary outcome analysis of switching from originator to adalimumab biosimilar

\begin{tabular}{|c|c|c|c|c|c|}
\hline Diagnosis & $\begin{array}{l}\text { Total } \\
\text { patient } \\
\text { switched } \\
\text { from } \\
\text { originator }\end{array}$ & $\begin{array}{c}\text { Average duration } \\
\text { (year) of use of } \\
\text { originator before } \\
\text { bio switch (for } \\
\text { patients continue } \\
\text { using bio switch) }\end{array}$ & $\begin{array}{c}\text { Total } \\
\text { patients } \\
\text { continuing } \\
\text { (At 12 } \\
\text { weeks) }\end{array}$ & $\begin{array}{l}\text { Average duration } \\
\text { (year) of use of } \\
\text { originator before } \\
\text { bio switch (for } \\
\text { patients switched } \\
\text { back to originator) }\end{array}$ & $\begin{array}{c}\text { Total } \\
\text { patients } \\
\text { switched } \\
\text { back to } \\
\text { origina- } \\
\text { tor or } \\
\text { other } \\
\text { biosimilar }\end{array}$ \\
\hline $\begin{array}{l}\text { Rheumatoid } \\
\text { Arthritis }\end{array}$ & 356 & 7.9 & $314(88 \%)$ & 4.9 & $\begin{array}{c}42 \\
(12 \%)\end{array}$ \\
\hline $\begin{array}{l}\text { Axial } \\
\text { Spondyloarthritis }\end{array}$ & 260 & 6.4 & $213(82 \%)$ & 4.5 & $\begin{array}{c}47 \\
(18 \%)\end{array}$ \\
\hline Psoriatic Arthritis & 218 & 5.9 & $187(86 \%)$ & 2.9 & $\begin{array}{c}31 \\
(14 \%)\end{array}$ \\
\hline Juvenile Arthritis & 16 & 3.7 & $14(88 \%)$ & 4.5 & $2(12 \%)$ \\
\hline Others & 5 & 2.2 & $2(40 \%)$ & 0.8 & $3(60 \%)$ \\
\hline Total & 855 & 7.0 & $730(85 \%)$ & 4.2 & 125 \\
\hline
\end{tabular}

Table 2. Reasons for back to originator or another biosimilar

\begin{tabular}{lclc}
\hline \multicolumn{2}{c}{ Reasons for back to originator or another biosimilar } \\
\hline \multicolumn{1}{c}{ Number back for Intolerance } & \multicolumn{1}{c}{ Number back for Inefficacy } \\
\hline $\begin{array}{l}\text { Painful injection } \\
\text { Pain/Others }\end{array}$ & 69 & BASDAI/Spinal Pain & 13 \\
$\begin{array}{l}\text { Rash/Allergic } \\
\text { reaction }\end{array}$ & 19 & TJC, SJC, VAS & 4 \\
Headache & 5 & DAS & 3 \\
Nausea & 5 & PsARC & 2 \\
Total & 4 & No Detail & 1 \\
$\%$ & 102 & Total & 23 \\
& $82 \%$ & & $18 \%$ \\
\hline
\end{tabular}

Conclusion: Switching to a biosimilar was successful in the vast majority of patients and is associated with significant saving. The list prices for originator Adalimumab is $£ 9,155 /$ person/year and $£ 8,238$ /person/year for biosimilar Adalimumab respectively [2]. By switching we will save approximately $£ 719,402$ per annum (9.2\% cost reduction).

\section{References:}

[1] NHS England. NHS set to save record $£ 300$ million on the NHS's highest drug spend 2018 [cited 2018 November 30]. https://www. england.nhs.uk/2018/11/nhs-set-to-save-record-300-million-on-thenhss-highest-drug-spend/

[2] https://bnf.nice.org.uk/medicinal-forms/adalimumab.html

Disclosure of Interests: Rifat Mazumder: None declared, Marianne Loke: None declared, Chetan Mukhtyar: None declared, Karl Gaffney Grant/ research support from: AbbVie, Celgene, MSD, Novartis, Pfizer, and UCB Pharma, Consultant of: AbbVie, Celgene, MSD, Novartis, Pfizer, and UCB Pharma, Speakers bureau: AbbVie, Celgene, MSD, Novartis, Pfizer, and UCB Pharma, Emese Balogh: None declared, Emerald Sekaran: None declared, Mushfika Sultana: None declared, Mabel Odonkor: None declared, Karen Miles: None declared

DOI: 10.1136/annrheumdis-2020-eular.4709

\section{AB1179 EMERGENCY DEPARTMENT LENGTH OF STAY FOR PATIENTS WITH ACUTE GOUT}

N. Mbuyi ${ }^{1}$, S. Reinert ${ }^{2}$, R. Hilliard ${ }^{3}$, A. Reginato ${ }^{3}$, D. Dalal ${ }^{3} .{ }^{1}$ George Washington University School of Medicine, Department of Medicine, Washington, DC, United States of America; ${ }^{2}$ Lifespan Health System, Providence, RI, United States of America; ${ }^{3}$ Warren Alpert Medical School of Brown University, Department of Medicine, Providence, RI, United States of America

Background: Emergency department (ED) visits for acute gout increased by approximately 20\% between 2006 and 2014 in the United States. (1) Reducing ED length of stay (LOS) can help improve health outcomes, and reduce ED crowding and cost of care for patients with gout.

Objectives: The aim of our study was to assess ED LOS and to identify factors associated with prolonged ED LOS in patients with acute gout.

Methods: In this retrospective analysis, we included the first ED visit of adult patients $(>18$

years) with acute gout who presented to the 3 EDs affiliated with Lifespan Health Systems, the largest healthcare provider in Rhode Island. Our study period was $3 / 30 / 2015$ to $9 / 30 / 2017$.

We calculated ED LOS as the time spent by patients in the ED until they were discharged. Patients presenting to the ED and subsequently admitted to the hospita were excluded given the differential effect of systems factors in these patients. We assessed the following factors' association with being in the upper quartile of ED LOS: (a) Patient factors - demographics, comorbidities and clinical presentation of gout (number of joints involved, severity as gauged by an ED triage nurse on a scale of 1 to 5 ; 1 being the worst) and (b) systems factors - time of day, day of the week, and time of year at presentation to the ED, teaching versus non-teaching hospital setting, and performing an arthrocentesis. We performed univariate and multivariable analyses to identify factors associated with prolonged ED LOS in patients with acute gout.

Results: A total of 355 patients (mean age $56.6 \pm 16.03$ years, $81.3 \%$ males) were included. The median ED LOS was 2.65 hours (1.75, 4.3 hours). A quarter of the patients spent more than 4.3 hours in the ED; the national average across all medical illnesses being 3.7 hours (2). In the univariate analysis, older age (> 65 years), comorbidities (hypertension, congestive heart failure), worse ED severity score, procedural delays, and teaching hospital setting were associated with being in the upper quartile of ED LOS. In a multivariable analysis, age $>65$ years, procedural delays, and worse ED acuity score continued to be associated with longer ED LOS.

Conclusion: In our study settings, patients with acute gout spent a longer time in the ED than the national median of 120-150 minutes. (2) We noted that older age and higher acuity score in addition to procedural delays led to longer length of stay in the ED. The results of our study should guide future interventions to reduce ED LOS for patients with acute gout. 